\title{
Analysis of Stress Inhomogeneous Coefficient of a Continuous Rigid Frame Bridge during Construction Stage
}

\author{
Jing-xian $\mathrm{SHI}^{1, \mathrm{a}}$, Zhi-hong $\mathrm{RAN}^{2}$ and Lu-chang $\mathrm{ZHAO}^{2}$ \\ ${ }^{1}$ Oxbridge College, Kunming University of Science and Technology,KunMing 650106, Yunnan, China \\ ${ }^{2}$ Yunnan University,KunMing 650106 Yunnan, China
}

\begin{abstract}
The box section which can meet the requirements of wider deck is widely used in the construction of continuous rigid frame bridge. However, the shearing force lag is very obvious, which causes the inhomogeneous distribution of stress in the cross section, and it may threaten the safety of the bridge structure when it is serious. Taking a continuous rigid frame bridge located in Yunnan, China as an example, this paper establishes the finite element calculation model of the bridge to analyze the stress inhomogeneity in the construction stage. The results show that the shear lag coefficient of the section is constantly changing during the dynamic process of construction, with the increase of the length of the cantilever, the shear lag coefficient gradually converges to 1 ; prestress is the most important factor that causes the lateral inhomogeneity of the positive stress.
\end{abstract}

\section{Introduction}

The box section which can meet the requirements of the wider deck is widely used in the construction of continuous rigid frame bridges. This kind of bridge has many characteristic such as spacing of the web is large, horizontal width of the flange is large, box wall is thin and so on. However, the shearing force lag is very obvious, which causes the uneven distribution of stress in the cross section, and it may threaten the safety of the bridge structure when it is serious.

The calculation model of construction monitoring for continuous rigid frame bridge generally adopts plane cross-section assumption,the whole longitudinal calculation by using bar program can not consider the shearing force lag effect. It is not safe or economical to calculate the shearing force lag coefficient based on experience. Taking a continuous rigid frame bridge located in Yunnan, China as an example, this paper mainly evaluates the cross-sectional stress inhomogeneity from the shearing force lag at construction stage and the stress concentration caused by prestress.

The object of this paper is a three spans prestressed concrete continuous rigid frame bridge on the freeway. The length is $370 \mathrm{~m}: 95+180+95 \mathrm{~m}$, and the elevation of the whole bridge is shown in Figure 1. The main beam is a single box and chamber variable section prestressed concrete continuous box girder, the standard width of the bridge is $12.0 \mathrm{~m}$, the design load is grade $\mathrm{I}$, the design speed is $80 \mathrm{~km} / \mathrm{h}$, and the design safety grade is I, he basic seismic intensity of seismic fortification is 7 degrees, the basic earthquake acceleration is $0.15-0.1 \mathrm{~g}$, seismic fortification measures are taken at 8 degrees.

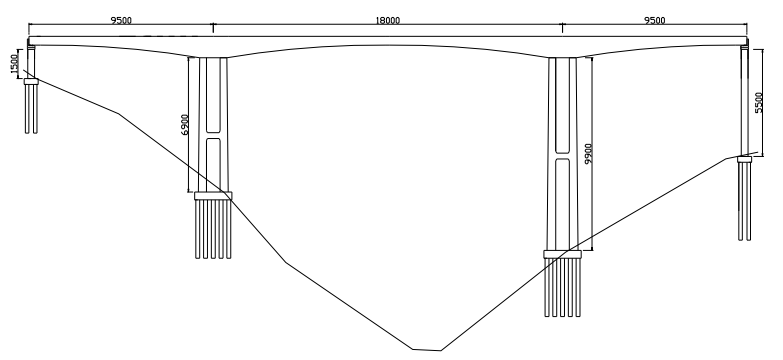

Figure1 The facade layout of the main bridge /cm

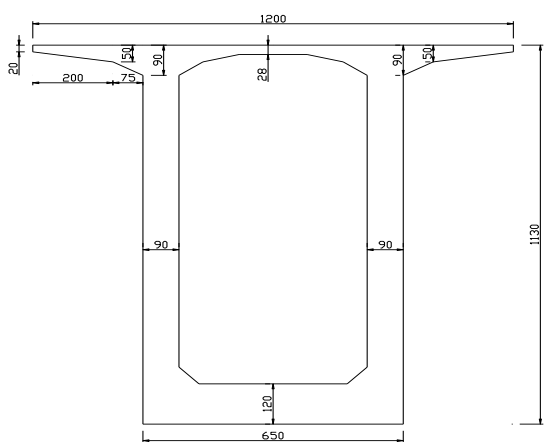

Figure 2 Standard section of the root of box girder $/ \mathrm{cm}$

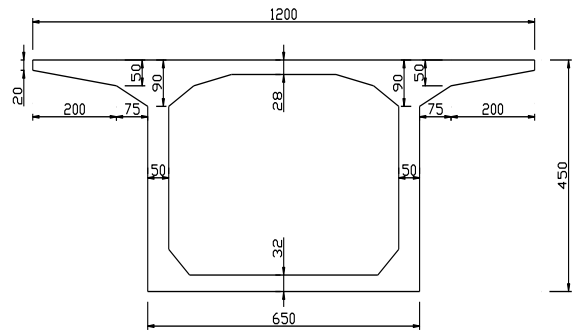

Figure 3 Standard section of box girder mid-span /cm

*Corresponding author: ${ }^{\text {a }}$ sara_shivip@ $163 . c o m$ 


\section{Analysis model}

The finite element model is selected by Midas/Civil and the structural parts of the bridge are divided into spatial structures. The finite element model is composed of 170 units, which are simulated in 65 construction stages according to the construction sequence of the actual construction process, and the bar system model is shown in Figure 4. The space object model is modeled by MIDAS/FEA. For the convenience of calculation, half structure is adopted to analyze. The $3 \mathrm{D}$ entity unit is adopted for the main girder and pier, and the calculation model is shown in Figure 5.

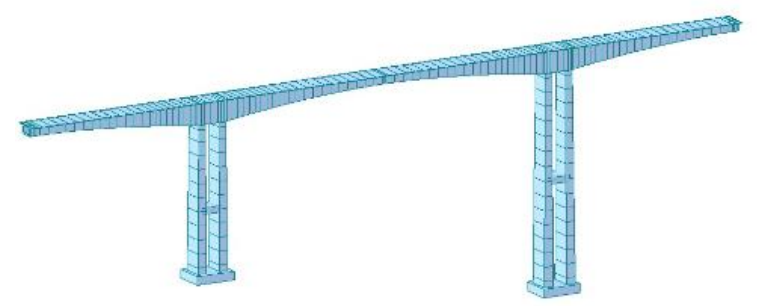

Figure 4 The plane bar system model of the bridge

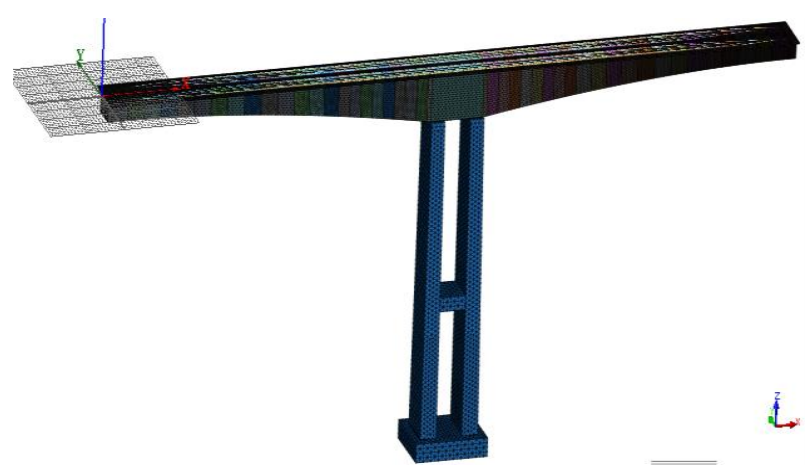

Figure 5 Solid model of bridge

\section{Analysis of stress unevenness in different construction stages}

Through the calculation results of the solid finite element model, the lateral stress distribution of the roof is shown in Figure 6.

(A) The normal stress distribution of the roof section is obvious after stretching 10\# beam prestressing tendon, and the stress concentration near the anchor point is obvious, as shown in figure 6-A. Through calculation and analysis, the shear lag coefficient increases from 1\# to $10 \#$, and increases uniformly in the first 8 items. The shear lag coefficient increases obviously near the free end of 9 and 10\#, the shear lag coefficient of the 1 section near the root is smaller. The maximum shear lag effect of the concrete under the 11 concrete block working condition is 1.140 . Although the shear lag coefficient is smaller but the average stress of the section is larger, the stress value is also larger, and it is likely to be the control stress of the whole beam section.

(B) After the prestressed tendons of the tensioned 15\# beam section, the calculation results of the finite element model of the concrete are obtained. The results show that the regular stress distribution of the concrete load, the prestressed tensile load and the hanging basket load on the top slab of the $1 \sim 15 \#$ concrete block is consistent with the following working conditions of the 10 block. The shear lag coefficient increased from block 1 to block 15 , and increased uniformly in the first 10 blocks. The shear lag coefficient of block 15 near the free end increased obviously. The shear lag coefficient at the edge of the roof is opposite to the shear lag coefficient in the 5 continuous working conditions, and the shear lag coefficient converges gradually from the free end to the section of the cantilever root.
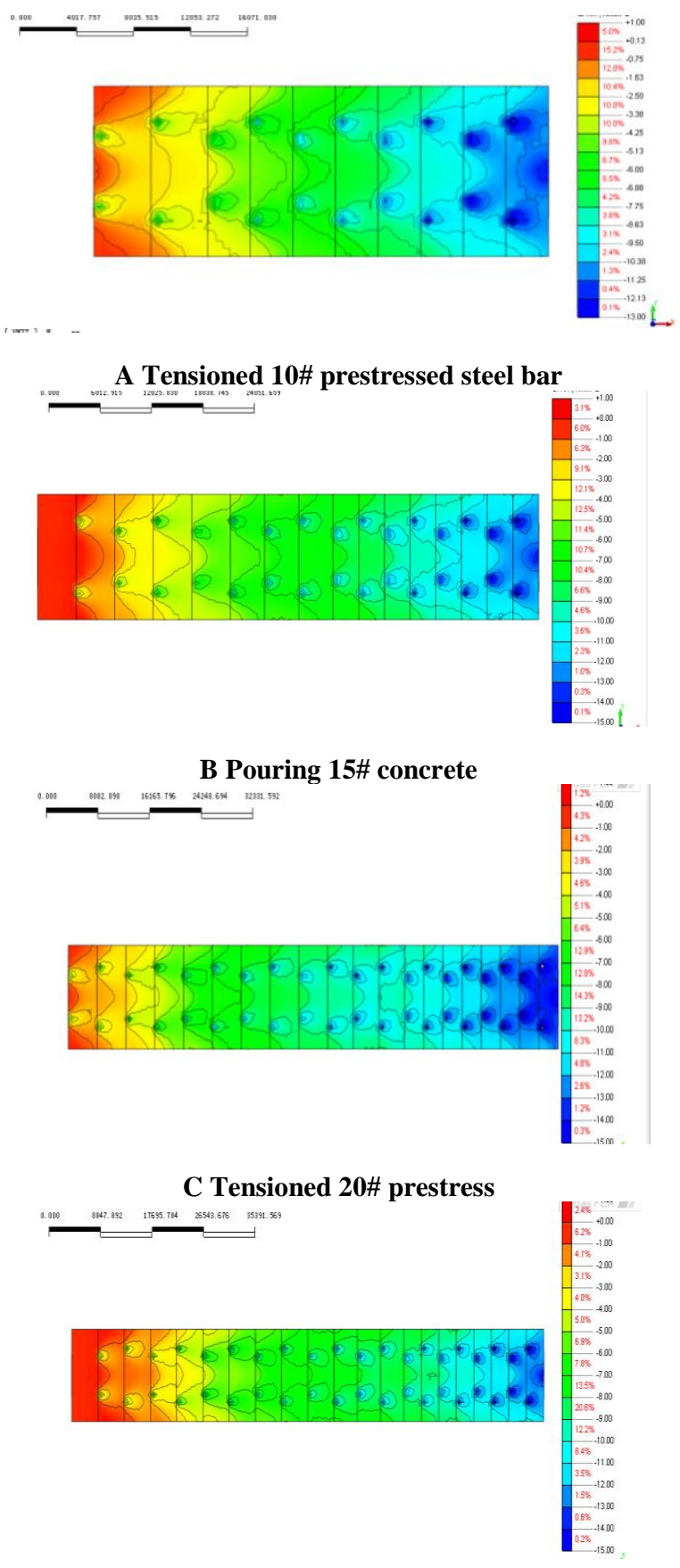

D Pouring 21\# concrete

Figure 6 Roof stress nephogram at different construction stages 
(C) Through tensile 20\# prestressed reinforcement and normal stress cloud picture of 21 \# concrete roof (Fig. 6$\mathrm{C}$ and $\mathrm{D})$, it can be seen that the normal stress curve distribution of roof section is very obvious. The absolute value of the position near the anchor point and the web of the prestressed steel bar is great, and the positive stress in the flange and the middle of the wing is very small. The stress near the anchored point of the prestressed reinforcement is obvious, and the trend of the normal stress cloud map in different construction stages is obvious. The shear force lag coefficient increases from $1 \#$ to $20 \#$, and increases uniformly at the front $15 \#$. The shear force lag coefficient of 16 20\# near the free end increases obviously.

Through the analysis of the above four different construction stages, it is known that the main factors affecting the shear lag coefficient in the construction stage are two load conditions of pouring concrete and tensioning prestress. The shear force lag coefficient is more than 1, which converges from the free end to the cantilever root section. At the junction of slab rib, the shear lag coefficient of each section increases when pouring concrete, and the shear lag coefficient of each section decreases when tension is prestressing, Therefore, in the bridge design, the layout of prestressed reinforcement and concrete block is optimized, which has great effect on the shear lag coefficient of control section. Most of the temporary loads in the construction process are consistent with the form of the hanging basket, all of which are local concentrated loads, which aggravate the shear lag effect.

\section{Distribution of normal stress under different loads}

Taking 1\# beam section as an example, the influence of self weight load, prestressed load and location of prestressed reinforcement on the uneven force is analyzed. Three MIDAS/FEA models are established for analysis: The distribution of positive stress only under the action of self weight; The normal stress distribution law of each section under the action of prestress only during the maximum cantilever construction stage. The normal stress distribution law of self weight + hanging basket + prestress is comparatively analyzed.

(A)Stress distribution law under the action of self weight

The normal stress distribution rule of $1 \#$ under different action is shown in Figure 7. In the middle of the $1 \#$ beam section, the effect of self weight load on the transverse distribution is small before the $7 \#$ is poured, and the growth of the top of the top of the roof is larger and the increase of the two sides is smaller after the $7 \#$ pouring. The maximum value of normal stress is obtained in the middle, and the minimum value is obtained at the edge of the roof, and the normal stress is non-uniform in transverse direction.

(B)Stress distribution law under prestress load It is shown from figure 8 that the transverse distribution of the positive stress in the $1 \#$ beam section is similar to that of the $\mathrm{W}$ shape at the $1-7 \#$ tension stage, and the minimum value is obtained at the edge and center, and the maximum value is obtained near the boundary of the slab rib. In the 10-21\# tension stage, the central section normal stress increases greatly, and the two sides increase slightly. As shown in the section of the river bed, the normal stress reaches the maximum value at the center section and obtains the minimum value at the edge.

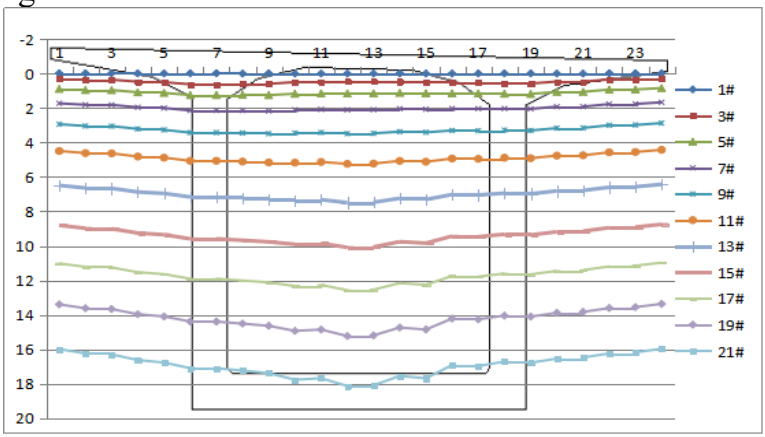

Figure 7 The distribution diagram of concrete normal stress under the action of self weight load

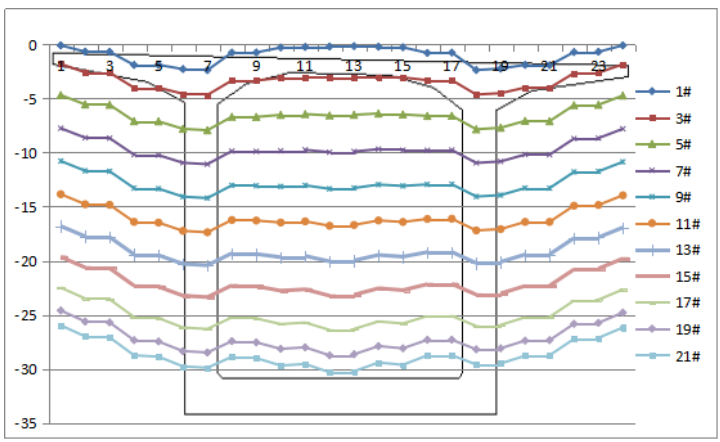

Figure 8 Normal stress distribution of concrete under prestressed loading

(C) Normal stress distribution law under self weight + hanging basket + prestressed load

From Fig.9,we can see that the normal stress distribution of $1 \#$ beam segment under three loads is similar to that of prestressed load, and the transverse distribution is similar to the $\mathrm{W}$ shape. the minimum value is obtained at the edge and center, and the maximum value is obtained near the boundary of the slab rib.

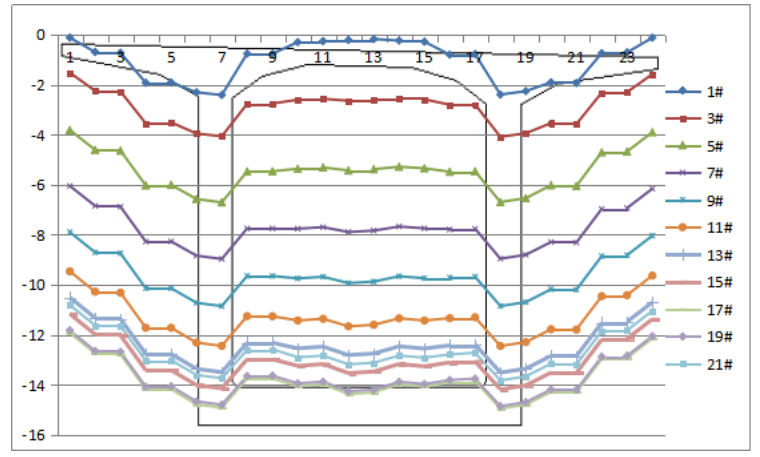

Figure 9 The distribution of positive stress in each tensioning stage under the action of self weight + basket + prestressed load 


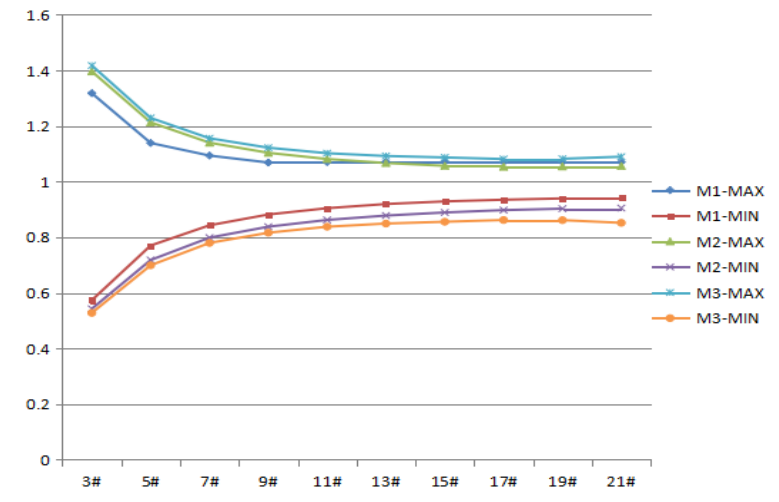

notes: M1 only represents the calculation model of self weight load in the figure, M2 only represents the calculation model of prestress load,M3 represents the simultaneous simulation of three kinds of loads.

Figure 10 Change diagram of shearing force lag coefficient of three models at each construction stage

The calculation shows that the variation trend of shear force lag coefficient is consistent with the independent action of weight, hanging basket load and prestressed load, and the shear force lag coefficient gradually converges to 1 with the increase of the length of the cantilever. Under the action of three loads, shear lag effect has addition gene effect. The stress difference of the M3 model is the largest, which indicates that prestress is the most important factor causing the lateral stress inhomogeneity; Self weight load has more and more influence on shear lag coefficient, but not the most important factor.

\section{Conclusion}

By establishing the finite element calculation model of the bridge, through the analysis of the stress distribution in the construction stage, we get the following conclusions:

1)The shear force lag coefficient of the section is constantly changing during the construction process. With the increase of cantilever length, the shear lag coefficient gradually converges to 1 .

2)Prestress is the most important factor causing the lateral stress inhomogeneity.

Therefore, it is of great significance to clarify the effect of self weight load, prestress load and prestress distribution position on shear force lag effect and reduce the shear lag effect of a long span continuous rigid frame bridge.

\section{References}

1. Song Q C, Scordelis A C. Formulas for shear lag effect of T- I-, and box beams, J.Struct. Engrg.,ASCE, 1990b, 116(5): 1306-1318.

2. Kristek V, Evans H R, Ahmad M K H. A shear lag analysis for composite box girders. J. Construct. Steel Research, 1990, (16): 1-21.

3. Chang S T. Shear lag effect in simply supported prestressed concrete box girder. J. Bridge Engrg., ASCE, 2004, 9(2): 178-184.
4. Sun F F, Bursi Q S. A displacement-based formulation for step-concrete composite beams with shear lag. In: Computational Modelling of Concrete Structures. Lisse: A Balkema Publishers, 2002, 827838.

5. Yang L F, Leung A Y T, Li Q S. The stochastic finite segment in the analysis of the shear-lag effect on box girders. Engrg. Struct.,2001,(23): 1461-1468.

6. Lertsima C, Chaisomphob T, Yamaguchi E. Stress concentration duo to shear lag in simply supported box girders. Engrg. Struct., 2004, (26): 1093-1101. 